\title{
法国城市政策中“社会混合” 原则的实施方式与效果研究
}

Social Mix in Urban Policies in France: Practices and Effects

摘要: 1990 年代以来, 随着社会隔离现象的凸显, “社会混合”被确立 为法国城市政策的重要原则。本文首先阐述了社会混合的涵义以及争 议, 进而以 2000 年颁布的《社会团结与城市更新法》和 2003 年开始的“国 家城市更新计划”为例, 分析了社会混合原则在法国城市政策中的实 施方式, 并对其实施效果进行综合评价。总体来说, 这些政策促进了 法国社会住房在城市空间上的均衡分布, 并且有效阻止了部分街区的 衰败趋势。但一些实证研究也暴露了其问题, 包括贫困人口异地再集中、 新居民融入程度不一、原有居民的异议等, 引发了对于社会混合实施 方式的探讨和改进。最后, 本文在总结法国经验的基础上对我国城市 如何应对居住分异以及社会隔离提出了建议。

Abstract: Since the 1990s, in the context of increasing social segregation, "social mix" has been regarded as an important principle of urban policies in France. This paper begins by clarifying the concept of social mix and the controversy over it, and then analyzes the mode of applying social mix through the case of SUR Law (loi Solidarité et Renouvellement Urbain) promulgated in 2000 and the National urban renovation program started in 2003, as well as the policy effects. In general, these polices promoted a more balanced distribution of social housing in urban spaces in France, and prevented a number of neighborhoods from continuously declining. Meanwhile, some empirical studies showed several negative effects, including the re-concentration of poor population in other neighbourhoods, the different degrees of integration among new residents as well as the discontent from original residents, etc.. Based on the French experience, implications are concluded for Chinese cities when facing residential and social segregation.

关键词：社会混合；社会住房；城市更新；居住迁移；法国

Keywords: Social Mix; Social Housing; Urban Renovation;

Residential Mobility; France

作者: 李明烨, 博士, 法中建筑与城乡可持续发展研究院 (IFADUR), 规 划师。minye.li@ifadur.com

汤爽爽, 博士, 副研究员, 南京大学地理与海洋科学学院。 sstang@nju.edu.cn

孙䒯, 同济大学建筑与规划学院, 博士研究生。zhonger1984@163.com

\section{引言}

1990 年代以来, 随着法国城市空间分异与居住隔离现 象的日趋严重以及由此带来的种种社会问题, “社会混合” 逐渐被确立为法国城市政策的基本原则。2000 年颁布的《社 会团结与城市更新法》(SRU: loi Solidarité et Renouvellement Urbain）对各市镇社会住房建设比重的强制规定标志着这一 原则已上升为一项国家政策，被普遍运用于法国城市住房规 划与建设中。2003 年起, 由法国国家城市更新机构 (ANRU: Agence Nationale de la Rénovation Urbaine) 主持的 “国家城 市更新计划” (PNRU: Programme National pour la Rénovation Urbaine）更是将社会混合作为指导思想和目标，针对隔离 严重的衰败街区实施了拆除社会住房、新建多样化的住房项 目、更新公共设施、改善交通可达性等改造措施。社会混合 与混居政策是西方学术界的重点研究领域, 但对于法国的个 案研究相对较少 ${ }^{[1-4]}$ 。部分国内文献对法国住房政策的发展历 程进行了梳理, 介绍了法国 1945 年一1970 年代中期快速城 市化背景下社会住房的大规模集中建设, 1980 年代居住隔 离的问题产生以及住房供给体系的多样化发展, 1990 年代 以来社会混合概念的提出以及城市更新战略的启动 ${ }^{[5.91}$ 。其中, 针对居住隔离问题的住房政策是研究的重点, 目的是吸取法 国的经验教训, 对我国保障性住房的建设提出建议 ${ }^{[7,8]}$ 。但 总体上, 现有研究对法国社会混合原则的阐述以法律及政策 导向的介绍为主, 对具体操作层面的考察和政策实施效果的 评估较少。事实上, 法国经过 10 多年的实践后, 已探索出 一系列实施社会混合原则的方式。从政策效果来看, 一方面, 自 SRU 法颁布和国家城市更新计划实施后, 社会住房的空 间分布较 1990 年代更为均衡 ${ }^{[10]}$, 衰败街区的面貌得到显著 改观；另一方面，法国城市的社会隔离问题并没有得到全面 的解决, 甚至在经济危机的背景下有所加深 ${ }^{[11]}$ 。部分实证研 
究表明：以 “分散” 贫困人口为目的的更新项目可能导致贫 困人口的异地再集中, 新居民在 “嵌人式” 的社会住房新增 项目中融入程度不一, 且部分原有居民对于来自不同阶层和 种族的家庭混居提出了异议。

由此, 本文以法国的经验为例, 以社会混合为切人点, 分析以 SRU 法和国家城市更新计划为代表的城市政策的实 施方式，并对其政策效果进行综合评价，最后对我国城市如 何应对居住分异以及社会隔离提出建议。

\section{1 “社会混合” 的涵义与争议}

法国《住房字典》(Dictionnaire de l'Habitat et du Logement）将 “社会混合” 定义为一项社会政策的目标，旨 在通过住房计划, 使不同社会阶层的人们能够在同一个城市 单元生活 ${ }^{[12]}$ 。相对于 “社会隔离”, “社会混合” 作为一项政 策目标, 是一个理想化的概念 ${ }^{[13]}$ 。前者是指因社会财富与城 市空间资源分配不公所导致的不同社会群体在空间上分隔的 现象, 以及由此逐渐加深的社会矛盾; 后者则展现了不同社 会群体在同一地理空间混合居住、和谐共处的理想愿景。面 对当前法国社会中不同阶层和种族之间的矛盾，决策者将社 会混合这一城市空间发展策略奉为缓解矛盾、促进社会融合 的“良方” “14]。

然而, 社会混合作为当前法国城市政策的基本原则仍存 在争议, 主要表现在两个方面 : 一是因其概念的模糊性而导 致的操作困难, 二是对其理论基础的质疑。

首先, 社会混合是一个模糊的概念, 具体表现在对于混 合的标准、程度与空间尺度没有明确的定义 ${ }^{[15]}$ 。不同人群在 城市空间上的混合, 可以有年龄、收人、种族、职业、阶层 等多重指标, 而采取哪些指标作为混合依据并不明确。目前 法国的城市政策主要根据家庭收人水平进行 “混合”。事实 上, 法国社会隔离问题的成因非常复杂, 除了经济收人水平 的差异外，还包括种族、宗教等方面的不同。其中，少数族 裔的居住隔离现象在法国大城市较为严重。以法兰西岛大区 为例, 1999 年共有 24 个市镇的非欧洲移民（包括后代）居 民比重超过 30\%, 占市镇总数的 6\%。然而, 法国国家统计 局曾声明涉及种族的指标具有政治敏感性, 因此仅统计人口 的出生地和国籍等 “中性化” 指标 ${ }^{[16]}$ 。考虑到法国的大规模 移民潮发生在 1970 年代之前, 移民后代大多已取得法国国 籍, 由此加大了以种族为指标的社会混合的难度。此外, 其 模糊性还体现在对于混合的程度和尺度没有明确的衡量依 据。例如, 各市镇社会住房比重界定是否合理, 混合的尺度 是一幢住宅楼、一个街区, 还是一个市镇等。社会混合概念 的模糊性导致了其在操作上的困难。

其次, 尽管社会混合已被确立为法国城市政策的基本原
则, 但其理论基础一直伴随着质疑。社会混合作为社会隔离 的对立面, 其合法性来自于贫困人口过度集中所产生的负面 “街区效应” ${ }^{1171}$ 。贫困人口的集聚造成地方税收的枯竭, 使 公共设施缺少维护, 进一步降低了街区的吸引力, 导致更多 贫困人口在此集中。这样, 街区境况陷人了恶性循环, 从而 走向持续的衰败 ${ }^{[18]}$ 。然而, 学术界对于社会混合本身的正面 效应尚存在争议。甘斯 (Gans) 提出了在街区尺度混合不同 人群的诸多益处, 包括丰富居民的生活, 利于下一代的教育 和个人发展, 加深不同阶层的彼此理解以及增强人们对阶层 差异的容忍度 ${ }^{[19]}$; 佛罗里达 (Florida) 指出, “混合” 创造 了不同文化的碰撞机会, 能激发城市的 “创造力”, 并提升 城市的经济与文化发展活力 ${ }^{[20]}$ 。但与此同时, 法国社会学家 尚博乐东和勒迈尔 (Chamboredon \& Lemaire) 指出 “空间 距离的接近不能缩减社会距离” ${ }^{[21]}$; 佩托内 (Pétonnet) 认为, 不能把部分社会群体在空间上的集中简单地视为社会隔离的 结果, 事实上也可能是他们自愿聚集 ${ }^{[22]}$; 某些社会群体因文 化、种族的因素在空间上聚集可能有助于团结协助, 而强制 性地将这些群体与主流群体混合反而可能导致少数群体受到 主流群体的控制和压迫 ${ }^{223]}$

\section{2 社会混合原则在法国城市政策中的实施方式}

10 多年来, 基于决策层的大力推动, 社会混合原则伴 随着以上质疑在法国的城市政策中得到广泛运用。在衰败街 区 “分散” 贫困人口和在富裕街区 “嵌人” 社会住房是当前 法国实现社会混合的主要方式。一方面, 政府通过“拆除一 重建” 和异地新增等方式推进社会住房在空间上的均衡分布 和与周边环境的有机衔接; 另一方面, 政府激励开发商在更 新项目进行商品房以及其他功能开发, 以实现街区人口与功 能的多样化。

\section{1 “分散” 与 “嵌入” 作为实现社会混合的主要方式}

国家城市更新计划和 SRU 法作为法国推动社会混合的 主要政策, 分别对应了 “分散” 和 “嵌人” 两大方式 : 前者 在空间上分散低收人家庭, 倡导多样化的住房供给, 改变问 题街区的形象; 后者在富裕街区嵌人式地新增社会住房, 吸 纳贫困家庭, 实现住房资源在城市空间上的均衡分配。

国家城市更新计划的主要改造对象为“城市敏感区” (ZUS: Zone Urbaine Sensible), 即法国政府基于失业率、收人、 社会住房比重等指标, 在城市内部划定的贫困人口过度集 中、社会问题突出的困难区域。城市敏感区内居民的贫困水 平是全国平均水平的 3 倍以上, 失业率高达 $20 \%$ 且为全国 平均水平的 2 倍以上, $60 \%$ 的居民住在社会住房内 ${ }^{[24]}$ 。贫困 人口在这些区域的集中一方面是社会住房在这些地区过度集 
中的结果 ; 另一方面是这些街区本身低劣的城市空间品质所 导致, 包括公共设施不足、公共和私有空间界限模糊, 以及 与周边城市环境的隔离。因此, 国家城市更新计划包含两大 措施: 一是通过拆除部分衰败的社会住房, 重新安置原有社 会住房居民, 新建产权形式多样化的住房, 实现分散贫困人 口的目标; 二是重新规划街区公共设施和公共空间, 提升街 区品质, 改变过去封闭的街区环境和负面的街区形象。更新 项目的具体操作包括项目编制、审核、批准、实施和评估等 五个阶段。市镇或市镇联合体 ${ }^{1}$ 为项目申请的主体, 负责与 社会住房的所有者一一低租金住房组织 (HLM: Organismes d'Habitations à Loyer Modéré) (2)共同编制项目规划, 经省政 府预审后提交至 ANRU。项目经过审核获得批准后, 项目主 体与 ANRU 签订协议, 获得 ANRU 资助。在项目实施期间, 评估和跟踪委员会 (Comité d'Évaluation et de Suivi) 作为由 建筑师、规划师、工会、记者、企业和社团代表等组成的独 立团体监督项目的实施, 重点考察更新项目对居民的住房、 工作和教育境况的改变情况, 并公布评估报告。其中, 项目 编制为关键环节, 只有较好地体现分散原则、改善街区环境 的项目才能获批。以克莱蒙费朗地区市镇联合体 2006 年获 批的城市更新项目为例, 改造方案包括拆除 537 套社会住房, 原地新建 230 套, 异地新增 307 套 (分别位于 18 个安置点) ${ }^{[25]}$ 。 拆迁对象的选择主要基于其所居住的社会住房的建筑状况, 而非拆迁家庭本身的情况。但在安置过程中, 拆迁家庭的意 愿会作为安置房分配的重要依据, 老年人、单亲家庭、多子 女家庭等弱势群体会被优先考虑安置在区位较好的街区 ${ }^{206]}$ 。

SRU 法第 55 条规定: 每个人口大于 3500 人的市镇（在 大巴黎地区, 每个人口大于 1500 人的市镇）的社会住房比 例都应达到 $20 \%$ 。未达到该比例的市镇将处以罚款, 罚金 将用以资助社会住房建设。2013 年颁布的《关于利用公有 土地建设社会住房以及加强社会住房建设责任》(loi Relative à la Mobilisation du Foncier Public en Faveur du Logement et au Renforcement des Obligations de Production de Logement Social) 法令, 又称 Duflot I 号法, 将这一比重提升到了 $25 \%$ 。该政策旨在通过新建、收购、更新等方式在社会住房 不足、富裕阶层集中的市镇内增加社会住房。自 SUR 法颁 布以来, 法国开始监测各市镇的社会住房建设进度, 定期公 布社会住房比例不达标的市镇名单, 并以三年为一个阶段制 定 “补建” 目标。在操作层面上, 由地方政府和低租金组织
代表组成的分配委员会（Commission d'Atribution）共同篮 选 “嵌人” 富裕街区的社会住房候选家庭。除了基本的收人 条件以外, 申请者的家庭构成、工作地点、所需公共服务设 施以及申请材料的紧急程度在分配时都将予以考虑。为了体 现公平原则, 不少市镇采取了积分方式, 对于就近工作者、 残障人士、单亲家庭、住房受灾者等指标赋予较高权重。

将 “分散” 和 “嵌人” 作为社会混合原则的实施方式, 与法国城市化发展阶段密切相关。法国早在 1970 年代就完 成了大规模的城市化进程, 当前的城市建设以更新改造为 主。因此, 社会混合的实施可以视作对过去规划模式所造成 的社会隔离现象的 “纠错” 过程。与此同时, 社会混合也成 为未来城市住房建设与开发模式的基本原则。法国规定各级 市镇联合体必须编制地方住房规划 (PLH: Programme Local de l'Habitat)。该规划基于本地区住房现状诊断, 制定未来 一个阶段 (一般为 5 10 年) 的新增住房计划, 在 SRU 法的 指导下明确不同类型住房的建设规模, 并参照地方城市规划 (PLU: Plan Local d' Urbanisme) 引导新增住房的空间分布。

\section{2 社会住房作为推动社会混合的有效工具}

鉴于社会混合标准的模糊性, 法国将社会住房视为实 现混合的主要工具。这一选择具有一定的合理性和可操作 性。2006 年, 法国 17\% 的家庭居住在社会住房中, 其中超 过 $60 \%$ 的社会住房居住家庭属于低收人家庭 ${ }^{3}$; 而 1992 年, 这一比重仅为 $52 \%{ }^{[27]}$ 。可见随着法国社会住房政策从 “一般 模式” 向 “剩余模式” 靠拢, 社会住房不再是中产阶级的社 会福利, 而集中保障贫困家庭 ${ }^{[28]}$ 。一般认为, 通过社会住房 在空间上的均衡分布可以促进不同收人家庭的混合居住。而 对于如何利用这一工具, 法国进行了多方面的探索。

(1) 在隔离严重的街区, “拆除一重建”社会住房, 在 异地新增社会住房。2003 年, 法国通过的《城市更新计划与 指导法》 (Loi d'Orientation et de Programmation pour la Ville et la Rénovation Urbaine), 又称 Borloo 法, 提出了在未来 5 年 ${ }^{\oplus}$ 内拆除 20 万套社会住房的计划, 拆除对象为位于城市 敏感区的大型社会住宅区 (Les Grands Ensembles) 内的不符 合居住标准的社会住宅。ANRU 规定在城市更新项目中拆除 社会住房后, 必须新增同等数量的社会住房, 其中约一半在 原街区重建, 另一半在其他街区新增。异地新增社会住房主 要通过新建、更新收购和协议收购三个渠道实现。其中, 更

\footnotetext{
(1) 由于大多数法国乡村市镇规模过小, 财力有限, 以市镇为单位的规划存在不集约、实施困难等问题。因此, 多个市镇基于共同的发展意愿联合 起来, 建立市镇联合体, 作为介于市镇和省之间的行政范围以及规划编制单元。

(2) 在法国, 低租金住房组织具有规划、开发、建设、更新、维护社会住房等多项职能, 是所开发建设的社会住房的所有者。

(3) 这里的“低收入家庭”是指收入水平根据 INSEE2 006 年统计的全法家庭收入最低的 $20 \%$ 和次低 $20 \% \sim 40 \%$ 的家庭。

(4) 后来这一计划从 5 年延长到了 10 年。
} 
新收购和协议收购在城市建设用地紧张、社会住房比重不足 的“富裕”市镇得到了广泛运用，在较短周期内实现了不同 类型住房的混合。以巴黎市为例, 富裕阶层集中的中心区以 及西郊更倾向于通过协议收购增加社会住房（图 1)。

（2）改变社会住房形式, 弱化社会住房建筑特征, 实现 社会住房与普通住房及周边城市环境的 “无痕” 衔接。法国 大型社会住宅区具有体量大、功能单一、与周边城市肌理格 格不人等特点 (图 $2 a, b$ )。随着贫困人口的集中, 这里的失 业、犯罪乃至毒品问题日趋严重, 导致了社会住房的 “烙印 化”。针对这一现象, 法国在近 10 年新建的社会住房摒弃了 城郊高层集体住房的形式, 转而采用低层、多层小型集体公 寓, 甚至联排别墅（图 3)。这些住宅在外观上与普通住房相 差无几, 符合现代建筑审美, 与周边环境相互融合 (图 2c)。 在城市用地使用效率上, 大型集体住宅由于受到日照间距、 公共绿地等指标的制约并不比多层小型集体公寓楼更加集约 (图 4) ${ }^{[30]}$ 。此外, 收购的社会住房与新建社会住房相比, 可更好地与周边环境融合。部分市镇甚至尝试收购高档社区
内的历史建筑来建设社会住房, 对深度的社会混合做进一步 尝试（图 2d）。

\section{3 激励开发商进行商品房以及其他功能开发}

在推动社会住房均衡分布的同时, 法国政府也积极鼓 励房地产开发商在社会住房过度集中的街区增加面向中产阶 级的商品房供给。相较于富裕阶层, 中产阶级更倾向于与其 他阶层的人群混合居住, 他们一方面对住房的价格比较敏 感, 另一方面具有较高的社会包容度。因此, ANRU 利用 税收政策鼓励开发商在更新项目 $300 \mathrm{~m}$ 半径的区域内进行商 品房建设。低于规定收人上限的购房家庭可以享受比市场价 格更优惠的房价, 而这一差价主要通过房产增值税率的优惠 （由 $20 \%$ 降至 5.5\%) 实现。同时, “土地住房协会”（AFL: l'Association Foncière Logement）作为法国 “1\%住房基金”（1\% logement) (1)下属的一个非营利性机构, 负责在更新区范围内 建设专用于出租的商品房。此外, 针对社会隔离严重的街区 功能单一的问题, ANRU 在更新项目中重新规划了街区功能
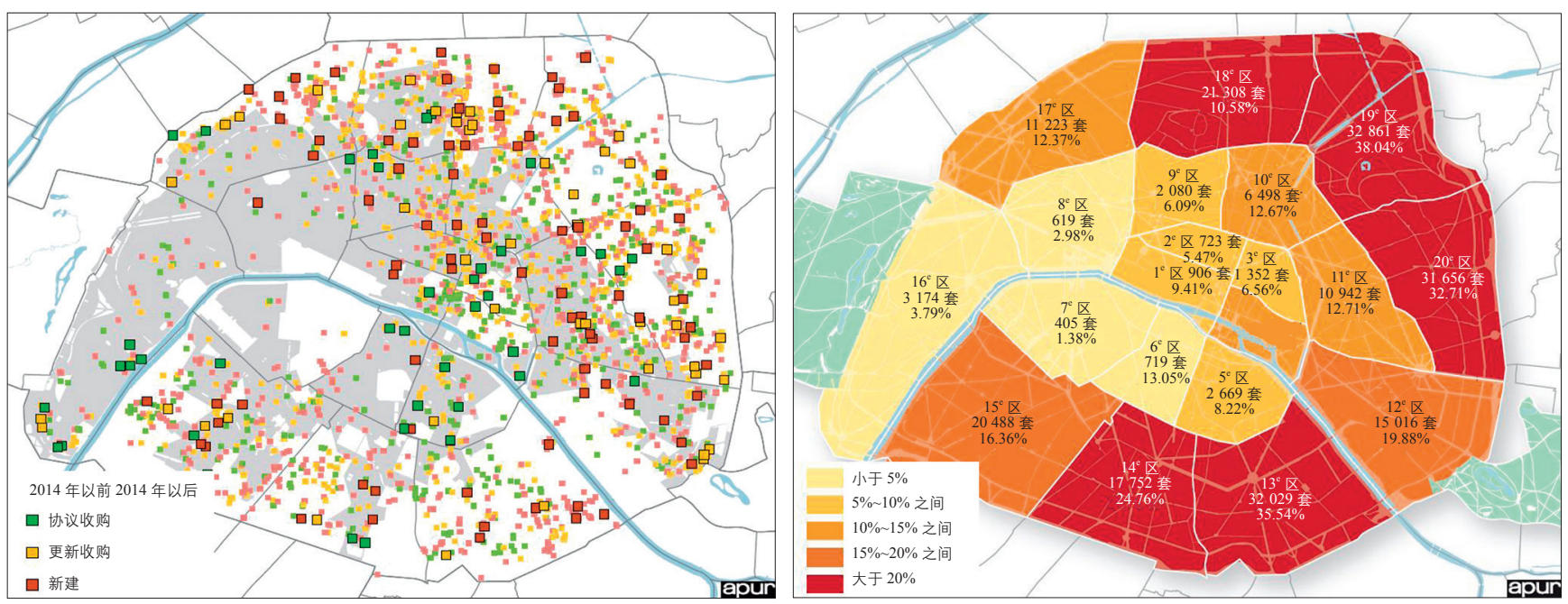

图 12014 年巴黎各区社会住房数量及比以及 2001一2014 年间巴黎社会住房新增方式 资料来源 : 参考文献 [29]

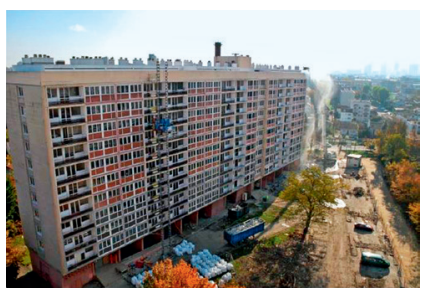

a. 郊区大型集体社会住房公寓

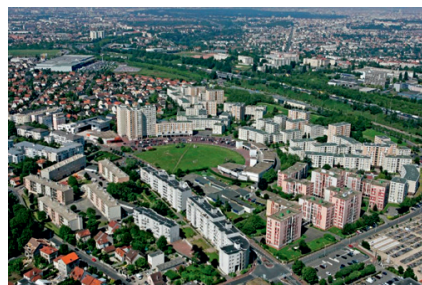

b. 郊区大型社会住房街区

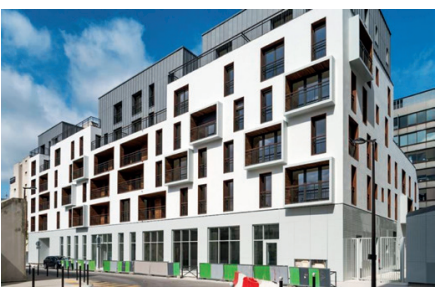

c. 新建的多层小型社会住房公寓

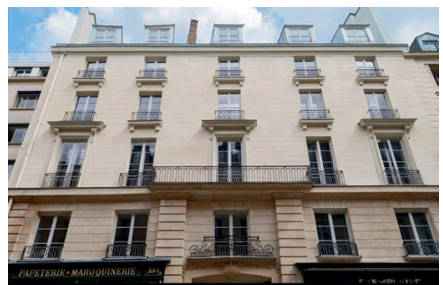

d. 历史街区内协议收购的社会住房

图 2 法国社会住房建筑形式

资料来源 : 图 a、b 源自参考文献 [30], 图 c、d 源自参考文献 [31]

(1) $1 \%$ 住房基金是法国的住房公积金项目，职工人数超过 20 人的企业必须将年度工资总额的 $0.45 \%$ 缴纳给该基金，用于资助企业职工租房或者 提供购房货款等。 
和空间组织方式, 引导开发商进行办公、商业设施的开发。 例如, 巴黎东南部克雷泰伊市镇的“小草地” (Petits Prés) 街 区更新改造项目包括 : 拆除 262 套社会住房, 原地重建 121 套社会住房, 新建 245 套普通住房, 住房总量由改造前的 262 套增加到改造后的 366 套, 住房密度提高了 $39 \%$; 同时, 小区的内部路网被重组和加密, 形成以 2 3 幢小型多层公寓 楼为单位的组团式结构; 匝道的拆除增加了街区的可建设面 积, 使小区东北角得以新建 $9000 \mathrm{~m}^{2}$ 的办公楼 ${ }^{[30]}$ (图 5)。

\section{3 社会混合原则的实施效果评估}

2000 年以来, 以 SRU 法和国家城市更新计划为代表的 法国城市政策积极推动了社会混合原则在城市政策中的实 施。总体上, 法国社会住房的分布较 1990 年代更加均衡, 部分衰败街区通过更新项目改变了负面形象, 提高了吸引力。 与此同时, 一些实证研究表明, 宏观层面的数据很可能掩盖 了这一政策对不同群体居住迁移路径的影响以及由此产生的 经济、社会、文化效应。

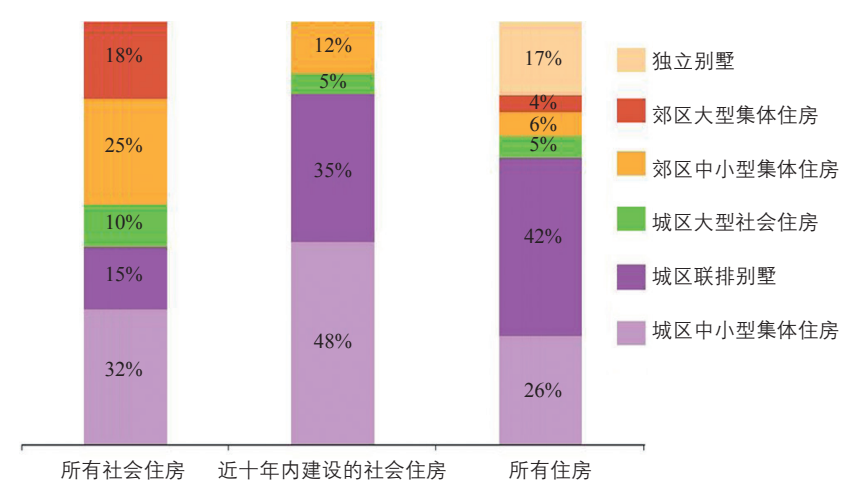

图 3 法国社会住房的建筑形式的转变 资料来源: 参考文献 [32]

\section{1 社会混合程度整体提升}

与 1990 年代相比, 当前法国社会住房的空间分布更为 均衡, 社会混合程度得到整体提升。1999-2011 年间, 法 国的社会住房数量从 410 万套增长到了 440 万套, 增长率 为 $7.5 \%$ 。其中, SRU 法涉及的未达标市镇在这期间的社会 住房总量增加了 $12.8 \%$, 社会住房在主要住所 ${ }^{1}$ 中的比重从 $10.4 \%$ 上升到 $11.1 \%$; 而 SRU 法涉及的达标市镇在这期间的 社会住房总量仅增加了 $3.8 \%$, 社会住房在主要住所中的比 重从 $30.6 \%$ 下降到 $29.8 \%{ }^{[33]}$ 。可见, 在 SRU 法的影响下, 未 达标市镇采取了更加积极的社会住房建设策略, 促进了辖区 内社会住房数量的增长。社会住房在空间上的均衡分布得到 推进。

\section{2 衰败街区吸引力增强}

在国家更新计划的干预下, 法国城市敏感区内的衰败 街区的面貌得到改观，吸引力有所增强。2003-2014 年间, ANRU 共计完成了 490 个更新项目, 投资总额为 470 亿欧元, 其中 ANRU 的直接投资为 123.5 亿欧元。这期间, 拆除 14 万套社会住房, 新增 14 万套社会住房, 重新安置 9 万户家庭。 此外, 更新计划范围内新增了约 8.5 万套普通住房, 实现了 住房供给的多样性 ${ }^{[34]}$ 。在法兰西岛大区, 衰败街区经过更新

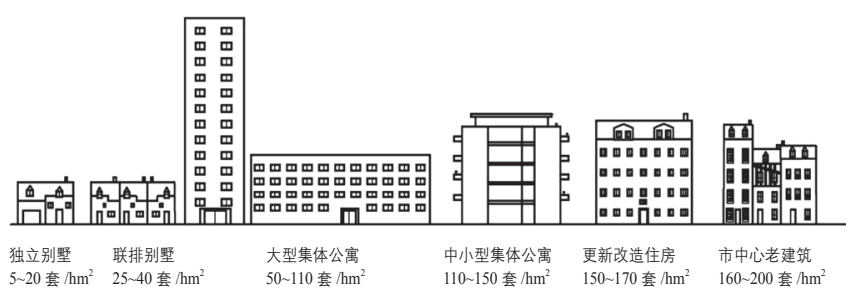

\section{图 4 法国不同住房类型建筑密度比较} 资料来源 : 作者根据参考文献 [30] 整理

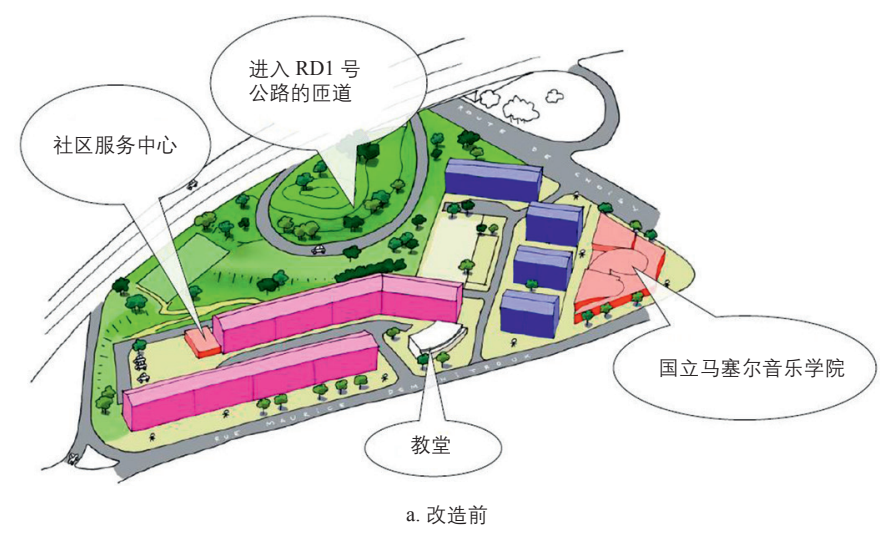

图 5 克雷泰伊市镇 “小草地” (Petits Prés) 街区改造前后对比 资料来源 : 作者根据参考文献 [28] 绘制

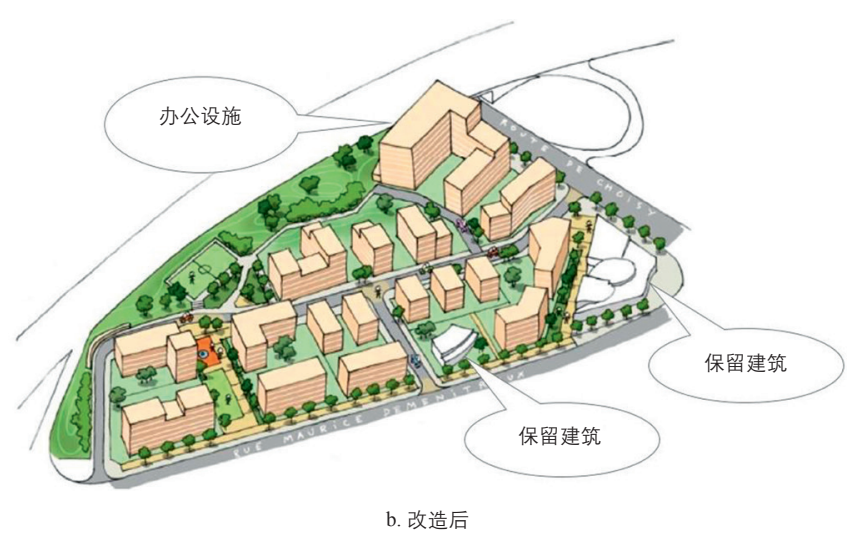

(1) 主要住所是相对于用于度假等用途的第二寓所而言的。 
改造以后, 购房人群中中高收人家庭比重增加, 街区平均房 价提高 ${ }^{[35]}$, 体现了街区吸引力的增强。

\section{3 贫困人口异地再度集中}

以“分散”贫困人口为目的的更新项目可能导致贫困人 口的异地再集中。基于法兰西岛大区 2004-2007 年间的 15 个国家城市更新项目的调查, 因更新项目迁出原住地的家庭 中, $75.9 \%$ 的家庭留在了同一个市镇内 ${ }^{1}$ 。其中, $89.9 \%$ 的被 安置家庭搬迁到了社会住房比重在 30\% 60\% 之间的市镇 ${ }^{[36]}$ 。 对于最贫困的家庭来说, 他们的居住迁移受到较多限制 : 首 先, 因不能接受租金上升, 他们只能被安置到租金较低的其 他大型社会住房区（往往位于城市敏感区）; 其次, 由于不 同市镇间尚未建立完全统一的社会住房供给网络, 跨市镇安 置的难度较大, 进一步减少了被安置贫困家庭的选择。因此, 更新项目尽管减少了项目范围内的贫困人口, 但导致了贫困 人口在其他城市敏感区的再集中。更新项目中的受益者主要 是通过优惠价格置业的 “小中产” 阶层, 更新项目使他们快 速实现了居住迁移路径的 “上升”。但由于他们中的很大部 分是移民或者移民后代 ${ }^{[36]}$, 以种族为指标的社会混合目标并 没有实现。

\section{4 新居民融入程度不一}

人迁富裕街区的低收人家庭尽管快速实现了居住迁移路 径的提升, 但因自身意愿的差异表现出了不同的融人和适应 程度。以迁人巴黎市中心以西的第 8 区两栋协议收购住宅 的低收人家庭为例: 一部分家庭的满意度较高, 主要源于 子女教育机会的改善、公共空间和设施的改善、通勤距离 的缩短 ${ }^{2}$, 他们自身也为融人新的街区付出了努力, 包括更 尊重街区内的环境及适应主流文化等; 另一部分家庭则有强 烈的边缘化感受，原因是他们在富裕街区很难找到廉价的商 品和服务, 疏远了居住在郊区的家人和朋友, 且受到更多歧

表 1 1999-2011 年 SRU 法对于不同市镇社会住房的影响

\begin{tabular}{l|l|l|l|l|l|l}
\hline & \multicolumn{2}{|c|}{$\begin{array}{c}\text { SRU 未涉及的 } \\
\text { 市镇 }\end{array}$} & \multicolumn{2}{|c|}{$\begin{array}{c}\text { SRU 涉及的已达 } \\
\text { 标市镇 }\end{array}$} & \multicolumn{2}{|c}{$\begin{array}{c}\text { SRU 涉及的未 } \\
\text { 达标市镇 }\end{array}$} \\
\hline 年份 & 1999 & 2011 & 1999 & 2011 & 1999 & 2011 \\
\hline $\begin{array}{l}\text { 社会住房在主要住所 } \\
\text { 中的比重 (\%) }\end{array}$ & 13.4 & 12.9 & 30.6 & 29.8 & 10.4 & 11.1 \\
\hline $\begin{array}{l}\text { 社会住房总量的变化 } \\
(\%)\end{array}$ & +6.0 & & +3.8 & & +12.8 & \\
\hline
\end{tabular}

资料来源 : 参考文献 [33]
视, 少数移民家庭甚至在人迁后又申请搬到其他街区 ${ }^{[37]}$ 。

\section{5 原有居民面临 “降级” ( déclassement ) ${ }^{3}$}

在富裕街区内新增的社会住房在提升新居民居住迁移路 径的同时, 也导致了原有居民迁移路径的被动下降。这里以 居住于巴黎第 9 区和第 15 区内被协议收购的两幢住宅的原 有居民为例。首先, 两幢住宅中分别有 $20 \%$ 和 $16 \%$ 的原有 居民在得知收购计划后搬离了原住宅。在第 9 区的收购住宅 中, 搬出家庭的平均月收人为 3695 欧元, 约为人迁家庭的 2 倍 ${ }^{1381}$ 。可见, 高收人家庭对于社会混合是排斥的。其次, 留下的家庭收人水平中等, 大多数对于收购行为表示不满。 他们的意见体现在 : (1) 收购过程中低租金住房组织和他们 的沟通不足; (2) 对需要缴纳比住在社会住房内的邻居更高 的租金表示不满；（3）感到自己的社会阶层有被 “降级” 的 危险；（4）不能接受人迁者（尤其是移民家庭）的文化习俗 和在公共空间的行为举止。可见, 原居民与新邻居的融合并 没有真正实现 ${ }^{[381}$ 。

\section{4 结论与启示}

\section{1 对法国经验的总结与探讨}

法国在快速城市化阶段集中建设的大型社会住房区加剧 了居住隔离, 进而引发了部分街区持续衰败、社会治安恶化 乃至郊区骚乱等严重的社会问题。社会混合被视为纠正这一 历史错误的补救措施。过去 10 多年间, 在决策者的大力推 动下, 法国城市成为实践社会混合原则的先行者, 积极探索 了在住宅楼、街区 (一般为城市更新项目的范围)、市镇等 尺度实现不同社会群体混合居住的方式, 并且取得了一定的 成效。在当前法国城市发展以更新改造为主导的背景下, “分 散” 和 “嵌人” 被确定为实施社会混合原则的基本方式。 2003 年起 ANRU 主持的国家城市更新计划和 2000 年颁布的 SRU 法, 分别对应这两种方式推动了社会混合原则在城市更 新过程中的实施。总体来说, 这些政策促进了社会住房在城 市空间上的均衡分布, 有效阻止了部分街区的衰败趋势, 对 城市空间的多样化发展和社会融合具有积极意义。然而, 一 些实证研究也暴露了这一政策存在的问题, 并引发了对社会 混合实施方式的探讨和改进。

（1）在进行物质空间改造的同时, 需要加强对个体家庭 住房境况的关注。当前的城市政策着眼于各个社会群体在特 定空间范围内按一定比例混合的静态结果, 而忽视了个体家 庭居住迁移路径上升或下降的动态过程。事实上, 公共政策

(1) 大多数法国乡村市镇规模较小, 四分之一的市镇人口少于 200 人, 二分之一的市镇人口少于 400 人。

(2) 低租金住房组织在选择保障对象时优先考虑了在富裕街区工作的低收入家庭。

(3) 此处的“降级” (déclassement) 特指社会学意义上人们从较高的社会阶层向较低的社会阶层流动。 
的介人可能导致部分家庭居住迁移路径上升, 也可能导致部 分家庭居住迁移路径下降。在这一过程中, 充分的沟通、人 性化的处理和适当的补偿措施尤为重要, 具体包括: 了解这 些家庭的住房需求、搬迁意愿、工作地点、经济承受力等; 根据家庭需求提供更适宜的、多样化的住房选择; 维持城市 更新项目内重建社会住房的租金水准, 不再增加贫困家庭的 住房负担等。

(2) 在推动 “外生性” 混合的同时, 激发和维护 “内生 性” 混合。当前法国的城市政策主要通过吸引外部新居民的 方式增加原街区的混合程度 ${ }^{[39]}$ 。新居民的到来可以给街区注 人新的活力, 创造不同文化的碰撞机会。与此同时, 原有居 民构建了亲友网络, 参与了社区公共事务, 培育了社区文化, 是社区发展的主导力量。与城市更新和新增社会住房相比, 保留原有居民的政策成本更低, 且可有效激发和维护社区的 内生性混合。例如, 法国从 1990 年代末开始尝试的减免附 加租金 (Exonération du Surloyer) 政策, 旨在保留社会住房 项目中收人水平提高且超过收人上限的家庭, 让他们为街区 混合贡献力量。

(3) 在短期内实现社会混合目标后, 需考虑如何在更 长时期内改善居民生活条件, 增进社会融合, 保持街区吸引 力。社会混合并非消除居住分异的终极策略。项目导向的居 住计划需要配合以 “人口” 导向的辅助政策来实现重建社区 的经济发展、社会晋升等目标 ${ }^{[40]}$ 。法国的经验显示, 针对更 新街区内失业人群的就业计划、社区服务中心提供的互助行 动等政策将在社区重建过程中起到关键作用。2014 年 2 月颁 布的《城市与融合计划》(Loi de Programmation pour la Ville et Cohésion Urbaine) 规定 ANRU 需要在城市更新项目中为当地 居民创造就业和职业培训机会, 例如, 在城市更新项目中新 建公共设施的维护和管理岗位时需优先考虑本街区内的居民。

\section{2 对我国城市应对居住分异的启示}

在市场转型和快速城市化的双重背景下, 我国城市居住 空间分异现象日益明显, 由此产生的社会经济问题也初见端 倪 ${ }^{[41]}$ 。法国的经验对我国城市应对居住分异具有现实意义, 具体体现在以下方面。

（1）重审我国城市更新改造中的拆迁安置方式。在激烈 的城市竞争背景下, 旧城改造成为我国地方政府实现城市功 能置换和提升的重要模式。然而当前的拆迁安置迎合了开发 商追求土地利益最大化的需求, 导致的结果是面向城市白领、 新贵阶层的高端居住区占据了公共资源集中、生活便利的优 越区位, 而中低收入阶层则被排挤到公共资源不足、可达性 差的边缘地区。从法国的经验来看, 城市政府作为土地利用 和空间规划的决策者应当突出公平原则, 将社会混合的理念
融人城市更新改造中, 增加原地安置比例, 提供多样化的异 地安置选择。同时, 在拆迁安置过程中, 应采取人性化的方式, 加强与拆迁对象的沟通, 充分尊重原居民的意愿, 优先考虑 弱势群体, 减少拆迁对于原居民家庭产生的负面影响, 让原 居民和新居民共享城市功能升级和空间改造的成果。此外, 可考虑设立独立的评估和跟踪团体以监督项目的实施情况和 居民的安置方式, 增加拆迁安置过程的透明度和公平性。

(2) 建立可持续的住房保障模式。自国家提出了 “十二五” 期间建设 3600 万套保障性安居住房的目标后, 地方政府需要在短期内完成相当数量的保障性住房建设指 标。受土地财政、扩张式城市发展模式以及中心区用地紧张 等因素的牵制, 许多城市政府选择了在郊区集中兴建保障性 住房小区。在快速完成保障指标的同时, 这一建设模式留下 了诸多隐患, 极有可能导致未来的居住隔离。对此, 国家应 当把住房保障定位为一项长期的住房政策, 而不是通过短期 内单纯的数量指标来实现保障性住房的大规模增长。相对于 实物保障来说, 住房补贴给予了保障对象更大的住房自住选 择权, 且能有效地避免低收人人口在特定空间的聚居, 可作 为未来住房保障的主要模式。地方政府在完成这一轮大规模 的保障房建设之后, 可考虑利用城市更新等契机在城市中心 地区逐步“嵌人” 保障性住房。在这些项目中应弱化保障房 的建筑特征, 实现不同住房类型间的 “无痕” 衔接, 以及保 障性住房与周边环境的有机结合。同时, 在住房供需矛盾不 突出的地区, 地方政府可采取收购商品房的方式增加保障房 供给。

（3）对少数族裔或移民聚居现象采取包容性的引导和改 造方式。从法国的经验看, 少数族裔移民家庭和主流群体的 混居具有一定的难度, 强行的混居可能造成居民之间更大的 矛盾。对此, 我国多民族混居的城市应包容适当程度的少数 族裔聚居现象, 并通过提供公平的教育和就业机会减少他们 与主流社会之间的差距, 使这一类型的社区在保持自身文化、 景观特色的同时朝着健康有序的方向发展。对于我国发达地 区的大城市来说, 移民聚居问题主要是城乡户籍和地区差异 造成的。大量外来务工人员在 “城中村” 聚居的现象屡见不 鲜。然而, 大部分 “城中村” 改造项目忽略了作为原居民重 要组成部分的农民工, 使他们被迫搬迁到更加偏远的地区, 形成新的聚居点。对此, 城市政府应该采取包容性的 “城中 村” 改造模式, 将原住民（包括租客）的居住需求考虑在改 造计划中，规划建设一定比例的与农民工支付能力相符合的 小面积出租房屋, 完善教育、医疗等公共配套服务, 实现未 来居住人口和社区功能的多样化发展。

（4）建设完整社区, 重建地方认同。住房改革以来, 以 小区为单位的房地产开发成为我国城市居住区发展的主要模 
式。和传统街区内的成熟社区相比, 这些小区很可能面临配 套设施不足等问题, 缺乏社会共同意识和邻里网络, 居民的 构成相对单一（往往是在房价因素下集聚的同一收人阶层的 家庭）。这些缺陷增大了城市内不同居住空间的不平等性, 加剧了居住分异。因此, “完整社区”建设是从微观层面上 促进社会融合的重要途径。对此, 法国在社区硬件和软件建 设方面的经验值得借鉴, 一方面充分重视街区公共空间的品 质, 完善配套设施, 加强小区与周边城市肌理的衔接; 另一 方面, 通过提供社区公共服务、组织文娱活动、扶助弱势群 体等一系列社区建设工作, 增强居民认同感, 激发和维护社 区的内生性混合, 保持社区吸引力。WPI

\section{参考文献}

[1]孙斌栋, 刘学良。美国居住混合政策及其效应的综合评述——兼论对 我国经济适用房和廉租房规划建设的启示 [J]. 城市规划学刊, 2009, 179(1): 90-97.

[2]孙斌栋, 刘学良. 欧洲混合居住效应的综合评述及启示 [J]. 国际城市规 划, 2010, 25(5): 96-102.

[3] 吉迪恩 - 博尔特, 罗纳德 - 凡 - 肯彭. 荷兰的社会混合与城市政策 [J]. 国际城市规划, 2013, 28(3): 8-12.

[4] 李志刚, 薛德升, 魏立华. 欧美城市居住混居的理论、实践与启示 [J]. 城市规划, 2007, 31(2): 38-44.

[5]赵明, 弗兰克・舍雷尔.法国社会住宅政策的演变及其启示 [J]. 国际城 市规划, 2008, 23(2): 62-66.

[6]刘健。城市快速发展时期的社会住房建设：法国的教训与启发 [J]. 国 际城市规划, 2012, 27(4): 3-12.

[7]陆超, 庞平, 居住隔离现象的内在机制探索与对策研究——法国大型 社会住宅建设对中国大型保障房建设的启示 [J]. 城市规划, 2013, 37(6): 52-56.

[8]王一, 张尚武. 法国《社会团结与城市更新法》对中国保障性住房建 设 [J]. 国际城市规划, 2015, 3(1): 42-61.

[9]孙莹、法国社会住房的政策演变和建设发展 [J]. 国际城市规划, 2016(5): 81-88.

[10] Rabault C, Hagmann C. Relever les Défis de la Crise du Logement en Ile-deFrance[R]. Livre Blanc de l'AORIF, Juin, 2014.

[11] Lelévrier C. Au Nom de la «Mixité Sociale»: Les Effets Paradoxaux des Politiques de Rénovation Urbaine[J]. Savoir/Agir, 2013(24): 11-17.

[12] Brun J, Segaud M, Driand J-C. Dictionnaire de L'habitat et du Logement[M]. Paris: Armand Colin, 2003.

[13] Charmes E. Pour une Approche Critique de la Mixité Sociale: Redistribuer les Populations ou les Ressources? [J/OL]. La Vie des Idées, 10 mars 2009. [2016-3-8]. http://www.laviedesidees.fr/Pour-une-approche-critique-de-lamixite-sociale.html.

[14] Genestier P. La Mixité: Mot D’ordre, voeu Pieux ou Simple Argument?[J]. Espaces et Sociétés, 2010(140-141): 21-35.

[15] Lefeuvre M-P, Lelévrier C, Drosso F, et al. La Mixité Sociale: Une Référence Européene Partagée? Comparaison Européene à Partir de la Référence Française: Allemagne, Espagne, Portugal[R]. Institut d'Urbanisme de Paris, 2006.

[16] Edmond Préteceille, Has Ethno-Racial Segregation Increased in the Greater Paris Metropolitan Area?[J]. Revue Française de Sociologie, 2011, 52(S): 31 62. DOI: $10.3917 / \mathrm{rfs} .525 .0031$.

[17] Wilson WJ. The Truly Disadvantaged: The Inner City, the Underclass and Public Policy. Chicago: University of Chicago Press. 1987.

[18] Atkinson R. Neighbourhoods and the Impacts of Social Mix: Crime, Tenure Diversification and Assisted Mobility[M]. Housing and Community
Research Unit/ ESRC Centre for Neighbourhood Research, 2005.

[19] Gans H. The Balanced Community: Homogeneity or Heterogeneity in Residential Areas?[J]. Journal of the American Institute of Planners, 1961, 27(3): $176-184$

[20] Florida R. The Rise of the Creative Class and How It's Transforming Work, Leisure, Community and Everyday Life[M]. New York: Basic Books, 2002.

[21] Chamboredon J-C, Lemaire M. Proximité Spatiale et Distance Sociale. Les Grands Ensembles et leur Peuplement[J]. Revue Française de Sociologie, 1970, 11(1): 3-33.

[22] Petonnet C. Ethnologie des Banlieues[M]. Paris, Edition Galilée, 1987.

[23] Remy J, Voyé L. Ville, Ordre et Violence[M]. Paris: PUF, 1981.

[24] Chevalier C, Lebeaupin F. La Population des Zones Urbaines Sensibles[R]. Insee Première, 2010, No.1328.

[25] ANRU. Convention ANRU Agglomération Clermontoise[OL]. (2006) [2016-3-18]. http://www.anru.fr/index.php/fre/Programmes/Conventions/ Convention-Agglomeration-Clermontoise.

[26] ANRU. Relogement, Insertion, Gestion de Proximité[OL]. (2014) [20163-20]. http://www.anru.fr/index.php/fre/Mediatheque/Publications/ Relogement-insertion-gestion-de-proximite-les-chiffres-au-30-juin-2014.

[27] Labrador J. Une Forte Hétérogénéité en Ile-de France[R]. Insee: Ile de France à la page, 2013, No. 414

[28] Driant J-C. Les Politiques du Logement en France[M]. Paris: La Documentation Française, 2009.

[29] Trevien C. Habiter en HLM: Quels Avantages, Quelles Différences?[R]. Division Marchés et Entreprises, Insee, 2013.

[30] Asselin T, Leonhardt F. L'Intensification dans les Projets de Rénovation Urbaine en Ile de France[R]. Contribution de l'ANRU à l'étude Menée par l’Observatoire Régional du Foncier d'Ile de France, novembre 2015.

[31] Nouvelle Moisson de Logements Sociaux dans les Beaux Quartiers Parisiens[N/OL]. (2015-01-06) [2016-3-20]. http://www.metronews.fr/paris/ photos-nouvelle-moisson-de-logements-sociaux-dans-les-beaux-quartiersparisiens/mofa!PXhCVjDHm47I/.

[32] APUR: Aterlier Parisien d'Urbanisme. Les Chiffres du Logement Social à Paris Début 2015[R]. 2015, No. 90.

[33] Vignolles B. Les dynamiques Locales dans le Logement Social de 1999 à 2011: L'Effet de la loi SRU[R]. Service de L'observation et des Statistiques, 2014, No. 195.

[34] Branco M, Besse-Le Saux S. Le Nouveau Programme National de Renouvellement Urbain 2014- 2024[R]. Dossier de Presse, Ministère de la Ville, de la Jeunesse et des Sports, 2014.

[35] Desponds D. Effets Paradoxaux de la loi Solidarité et Renouvellement Urbains (SRU) et Profil des Acquéreurs de Biens Immobiliers en Île-deFrance[J]. Espaces et Sociétés, 2010(140-141): 37-58.

[36] Lelévrier C. La Mixté dans la Rénovation Urbaine: Dispersion ou Reconcentration[J]. Espaces et Sociétés, 2010(140-141): 59-74.

[37] Launay L. Des HLM dans les Beaux Quartiers. Les Effets de la Politique de Mixité Sociale à Paris[J/OL]. Metropolitique, Nov, 2012. [2016-3-25]. http:// www.metropolitiques.eu/Des-HLM-dans-les-beaux-quartiers.html.

[38] Bacqué M-H, Fijalkow Y, Flamand A, et al. Comment nous Sommes Devenus HLM: Les Opérations de Mixité Sociale à Paris dans les Années 2000[J]. Espaces et Sociétés, 2010(140-141): 93-109.

[39] Gaudant N. La Mixité Sociale: Objectif ou Résultat des Projets de Rénovation Urbaine? [J/OL]. Metropolitique, Jan, 2013. [2016-3-20]. http:// www.metropolitiques.eu/La-mixite-sociale-objectif-ou.html.

[40] 李甜, 宋彦, 黄一如. 美国混合住区发展建设模式研究及其启示 [J]. 国 际城市规划, 2015, 149(5): 83-90.

[41] 孙斌栋, 吴雅菲。中国城市居住空间分异研究的进展与展望 [J]. 城市规 划, 2009, 33(6): 73-80.

(本文编辑：王枫) 